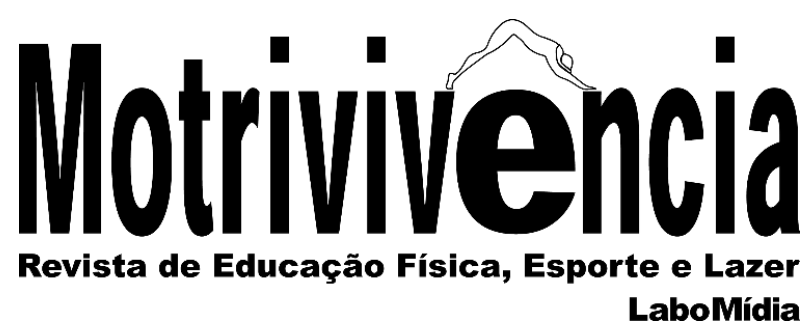

\title{
A Educação Física e a identidade étnico-racial: o estado da arte nas revistas brasileiras de Educação Física
}

\section{RESUMO}

O artigo trata do "estado da arte" que objetivou identificar, em quatro revistas que publicam estudos da Educação Física, as produções acadêmicas relacionadas com as questões étnicoraciais. Utiliza as palavras/conceitos: identidade, afro, étnico, cultura e etnia. Foram analisados 17 artigos contendo em sua discussão central elementos étnico-raciais. $\mathrm{O}$ recorte temporal decorreu de janeiro de 2013 a janeiro de 2018. Para facilitar o entendimento do conjunto dos trabalhos, eles foram divididos em blocos agrupando temáticas em comum. O processo posterior foi a análise da discussão dos conceitos, buscando a compreensão dos significados no interior de cada artigo elencado. A ordenação em bloco permitiu perceber as características e o tratamento do objeto conceitual, nos mostrando, ainda, uma ausência nas discussões étnico-raciais no que diz respeito ao Esporte e Educação.

PALAVRAS-CHAVE: Identidade; Esporte; Étnico; Racial; Afro
Pamela Tavares Monteiro

Graduada em Educação Física Universidade Federal do Espírito Santo - UFES

Vitória, Espírito Santo, Brasil

pamelamont@hotmail.com https://orcid.org/0000-0001-9380-0370

José Luiz dos Anjos

Doutor em Ciências Sociais

Universidade Federal do Espirito Santo - UFES

Departamento de Desportos

Vitória, Espírito Santo, Brasil

Jluanjos1@,com.br 


\title{
Physical Education and Ethnic-racial Identity: reflection of the state of the art in the publications of brazilian Physical Education
}

\begin{abstract}
The article covers the "state of the art" and it aimed at identifying, in four journals that publish physical education studies, academic productions related to ethnic-racial issues. It made use of the concepts: identity, afro, ethnic, culture and ethnicity. 17 articles were analyzed containing in his/her discussion central ethnic-racial elements. The time frame of the research was from January from 2013 to January from 2018. To facilitate understanding of the articles, the articles were set into blocks according to common themes. The subsequent process was the analysis of the discussion of the concepts, investigating the understanding of the meanings inside each of the listed articles. The separation of the articles into bocks enable the observation of the characteristics and the treatment of the conceptual object. An absence in ethnic-racial discussions regarding sport and education has been identified.
\end{abstract}

KEYWORDS: Identity; Sport; Ethnic; Racial; Afro

\section{La Educación Física y la identidad étnico-racial: el estado del arte en las revistas brasileñas de Educación Física}

\section{RESUMEN}

El artículo que trata del "estado del arte" tuvo por objetivo identificar, en cuatro revistas que publican estudios de Educación Física, producciones académicas relacionadas con las cuestiones étnico-raciales. Utiliza las palabras/conceptos: identidad, afro, étnico, cultura y etnia. Se analizaron 17 artículos que contenían en su discusión central elementos étnico-raciales. El recorte temporal transcurrió desde enero de 2013 hasta enero de 2018. Para facilitar el entendimiento del conjunto de los trabajos, los artículos se dividieron en bloques agrupando temáticas en común. El proceso posterior fue el análisis de la discusión de los conceptos, buscando la comprensión de los significados en el interior de cada artículo enumerado. La ordenación en bloque permitió percibir las características y el tratamiento del objeto conceptual. Se ha identificado una ausencia en las discusiones étnico-raciales sobre deporte y educación.

PALABRAS-CLAVE: Identidad; Deporte; Étnico; Racial; Afro 


\section{INTRODUÇÃO}

A importância da análise do estado da produção científica vigente numa área de pesquisa é múltipla. Ela pode detectar teorias e métodos dominantes; pôr em discussão aspectos do objeto de estudo que se esboçam nas entrelinhas das pesquisas; revelar em que medida a pesquisa recente se relaciona com a anterior e vai tecendo uma trama que permite avançar na compreensão do objeto de estudo pela via do real acrescida da articulação do pesquisador e da superação de concepções anteriores. Assim podemos avaliar as continuidades e descontinuidades teóricas e metodológicas e o quanto a produção atual se faz por repetição ou ruptura, ou seja, o quanto avança na produção de saber sobre o objeto de estudo.

O estudo do ensino das relações étnico-raciais vem ganhando destaque nos últimos anos, o âmbito escolar, a efetivação da Lei de $n^{\circ}$ 10.639/2003, Lei de Diretrizes e Bases (LDB), em 2003, trouxe a obrigatoriedade escolar do ensino da História e Cultura Afro-Brasileira e Africana nas grades curriculares dos ensinos fundamental e médio.

Sendo assim, é pertinente estudar as questões étnico-raciais produzidas/publicadas, procurando refletir sobre a temática diversidade racial na Educação Física já que, como afirmado por Sales e Almeida (2015, p.136), a Educação Física possui elementos e conteúdos que podem ser debatidos e pedagogizados oferecendo subsídios para a discussão étnico-racial.

Também é necessário salientar de forma crítica que as publicações geram inquietações no pesquisador, pois favorecem questionamentos, após escolher a temática, tais como: quais são os temas mais focalizados? Quais as metodologias empregadas? Quais as contribuições e pertinência dessas publicações para a área da Educação Física? Quais mudanças nas perspectivas pedagógicas na Educação Física? O que é, de fato, específico de uma determinada área da Educação e da Educação Física: a formação de professores, o currículo, a formação continuada ou as políticas educacionais? No entanto, para nós que empreendemos este estudo, parece que o interesse pelos temas educacionais que tratam das questões étnico-raciais não tem sido suficiente para que mudanças significativas ocorram nos espaços de formação escolares ou não escolares.

Objetivamos, então, identificar o estado da arte nas principais publicações das revistas/periódicos acadêmicos brasileiros referentes à Educação Física, no período de janeiro de 2013 a janeiro de 2018. Esse período foi politicamente escolhido para verificação de como se encontram as publicações voltadas para as temáticas étnico-raciais posteriores ao interregno 20032013, porque recebeu os maiores apoios governamentais para as políticas públicas voltadas à população negra brasileira (CARVALHO, 2018, p. 213). Entendemos que as análises deverão 
apontar para um mapeamento que desvende e examine o conhecimento já elaborado/publicado e apontem os enfoques e os temas mais pesquisados.

O corpus sobre o qual incide este estudo limita-se às publicações das matrizes teóricas da História, estudos da Sociologia e Antropologia e Educação Física. Os periódicos/revistas científicos analisados foram: a) Revista Brasileira de Ciências do Esporte (RBCE) (B1), editada sob responsabilidade institucional do Colégio Brasileiro de Ciências do Esporte (CBCE); b) Revista Movimento (A2), que é uma publicação da Escola de Educação Física da Universidade Federal do Rio Grande do Sul; c) Revista Pensar a Prática (B1), que publica artigos relacionados com o campo acadêmico-profissional da Educação Física e é editada sob a responsabilidade institucional da Faculdade de Educação Física e Dança da Universidade Federal de Goiás; d) Revista da Universidade Estadual de Maringá (UEM) (A2), que publica artigos originais na área de Saúde.1

As edições das revistas/periódicos foram metodologicamente encontradas em suas plataformas on-line. Em cada publicação, os resumos eram lidos e procurados no seu interior os prefixos: afro/afra e também palavras como raça, cultura, identidade, étnico/etnia, racial, negro/negra, capoeira e a Lei de $n^{\circ} 10.639 / 2003$. Quando encontrado algum prefixo, avaliávamos se havia recorte étnico-racial no conteúdo; caso houvesse, líamos o artigo na íntegra. Posteriormente, para seleção dos artigos, foram analisados os conteúdos, separados por conceitos, referentes às discussões étnico-raciais. Porém, devido à escassez de trabalhos voltados especificamente para tal temática, os artigos que traziam outras problematizações étnicas e/ou raciais também foram citados.

$\mathrm{Na}$ busca das publicações, levantamos 17 artigos que realizaram discussões étnico-raciais, tendo como objeto de discussão os prefixos e sufixos elencados. Os artigos foram divididos nas categorias: Aplicabilidade da Lei de $n^{\circ}$ 10.639/2003; Capoeira; Jornalismo; Tradição e Cultura; Raça, Eugenia e Identidade; Marketing e Estereótipos Corporais; Políticas Públicas. Neste trabalho, utilizamos a análise do conteúdo (quanti qualitativo). Uma vez coletados os dados (conceitos), o passo seguinte foi a classificação em blocos em sua integridade. O processo posterior foi o a análise da discussão dos conceitos, quando buscamos a compreensão dos significados no interior de cada artigo elencado.

\section{LEVANTAMENTO QUANTITATIVO DOS ARTIGOS}

Para dimensionar os 17 artigos, fizemos o levantamento anual da produção acadêmica voltada para as questões étnico-raciais na Educação Física, conforme a tabela a seguir:

\footnotetext{
${ }^{1}$ Quallis/Capes das revistas assinaladas em janeiro de 2018
} 
Tabela 1- Quantitativo de produções étnico-raciais nos periódicos da Educação Física em relação ao ínterim 2013-2018

\begin{tabular}{lllllll}
\hline & \multicolumn{7}{c}{ ANO } \\
\cline { 2 - 6 } & 2013 & 2014 & 2015 & 2016 & 2017 & 2018 \\
\hline $\begin{array}{l}\text { QUANTIDADE DE } \\
\text { ARTIGOS }\end{array}$ & 01 & 03 & 04 & 04 & 04 & 01 \\
\hline
\end{tabular}

Fonte: os autores

Os 17 artigos foram agrupados nos seguintes blocos:

- Aplicabilidade da Lei de $n^{\circ}$ 10.639/2003: PIRES, J.V.L., SOUZA, M.S. (2015); SILVA, E.V.M e MATTHIESEN, S.Q. (2018); BINS, G.N., MOLINA NETO, V. (2017).

- Capoeira: CUNHA, M.C.F., VIEIRA, L.R., TAVARES, L.C.V., SAMPAIO, T.M.V. (2014).

- Tradição e Cultura: ANJOS, J.L. (2013); MAROUN, K. (2014); SANTOS, S., PIMENTEL, G.G.A. (2015); DEBORTOLI, J.A.O., COSTA, K.T.O. (2016); SBORQUIA, S.P., DALBEN, A. (2017).

- Raça e Eugenia e Identidade: GALAK, E.L. (2014); LISE, R. S., SOUZA, M. T. O., JENSEN, L., CAPRARO, M.A.(2015); ABRAHÃO, B. O. L., SOARES, A.J.G. (2016, 2017); TRALCI FILHO, T.A., SANTOS, A.O. (2017).

- Marketing e Estereótipos Corporais: GODOI, M., DUMMEL, M.A.L., SILVA SÁ, R.B. (2016); MIGLIORATI, M., ARANDA, A.F., GONZALEZ, R.C. (2016).

- Políticas Públicas: NEVES, R.L.R., GOLIN, C.H., LIRA, L.C., SAMPAIO, T.M.V., ASSUMPÇÃO, L.O.T. (2015).

No interior dos artigos, observamos que as definições e conceitos das vertentes étnico-raciais estavam ligadas ao campo dos estudos socioculturais. Os autores clássicos citados nos artigos foram: Hall (2003), Canclini (2000), Evans-Pritchard (1968), Dunning (2014) e D'adesky (2005). Abordando conceitos étnico-raciais na educação, encontramos Gomes (2017) e Nogueira (2007). Os dois últimos autores foram utilizados para discutir problemáticas das relações étnico-raciais, entretanto alertamos para a falta de busca de referências na, já não rara, produção brasileira sobre ou relacionada com relações étnico-raciais e Educação Física. No processo de análise, citamos parcialmente os registros principais e os destacamos sem, contudo, indicar a referência, entendendo que se trata do próprio texto analisado. 


\section{OS CONTEÚDOS DOS BLOCOS TEMÁTICOS}

\begin{tabular}{|c|c|c|c|}
\multicolumn{4}{c|}{ Quadro 1 - Capoeira } \\
\hline Título do artigo & Origem & Método & Autores e ano \\
\hline $\begin{array}{l}\text { Capoeira: a memória } \\
\text { social construída por } \\
\text { meio do corpo }\end{array}$ & $\begin{array}{c}\text { UCB/ IFS Pós- } \\
\text { graduação }\end{array}$ & $\begin{array}{c}\text { Pesquisa } \\
\text { bibliográfica }\end{array}$ & $\begin{array}{c}\text { CUNHA, VIEIRA, } \\
\text { TAVARES e } \\
\text { SAMPAIO (2014) }\end{array}$ \\
\hline
\end{tabular}

Fonte: os autores

O bloco "Capoeira" (Quadro 1) nos remeteu à discussão étnica voltada para a memória da construção e desenvolvimento da capoeira. O objetivo do artigo de Cunha et al. (2014) foi compreender, por meio de uma análise de elementos da história da capoeira, os mecanismos de busca por legitimação no seu universo, bem como suas diferentes formas de organização e manifestação preservadas na memória e cultura brasileira. Esses autores entendem a memória social como instrumento analítico reflexivo para compreender melhor os processos de formação das identidades em uma nação.

Os autores discorrem sobre os conceitos de memória e identidade. Na construção do discurso, narram fatos passados os quais são trazidos à luz do presente, de maneira a dar coerência cronológica para os que discursam e desejam construir um sentimento de identidade. Falam sobre a memória da capoeira, sobre personalidades que ressignificaram sua prática, sobre a criminalização desta e citam os dois mestres importantes no decorrer desse cenário, Mestre Bimba e Mestre Pastinha, as principais figuras míticas que são referências aos praticantes da capoeira.

Pertencentes a vertentes antagônicas, Mestre Bimba buscava uma capoeira de manifestação artística, mestre Pastinha entendia a capoeira com origens e expressões africanas. A grande discussão étnica rodeia em torno das problemáticas que uma capoeira, como manifestação artística, pode gerar. Assim, surgem manifestações racistas em favor do branqueamento, apoiados pela Educação Física militarista. Inezil Penna Marinho é citado por seu livro: "Subsídios para o estudo da metodologia do treinamento da capoeiragem" (1944), no qual apoiava a miscigenação com discursos racistas, citando o mulato como ideal para a capoeira: "[...] tipo ideal da capoeira por ser mais inteligente que o negro e mais destro do que o branco". Annibal Burlamaqui, também conhecido como Zuma, ganha destaque nessa obra ao desejar "embranquecer" e elitizar a capoeira com discursos e obras militaristas em favor da esportivização desta prática.

Os autores abordam o contexto pluralizado no qual há na capoeira um enquadramento governamental no viés da cultura que dificulta seu entendimento mais amplo. Sendo assim, os autores concluem que a capoeira segue com múltiplos discursos de legitimação, agora, por vezes, 
mais ancorados e equalizados ao degrau de ascensão que foi dado pelo seu registro como patrimônio cultural brasileiro.

Quadro 2 - Aplicabilidade da Lei de $\mathrm{n}^{\circ}$ 10.639/2003

\begin{tabular}{|c|c|c|c|}
\hline Título do artigo & Origem & Método & Autores e ano \\
\hline $\begin{array}{c}\text { Educação Física e a } \\
\text { aplicação da Lei no } \\
\text { 10.639/03: análise da } \\
\text { legalidade do ensino } \\
\text { da cultura afro- } \\
\text { brasileira e africana } \\
\text { em uma escola } \\
\text { municipal do RS }\end{array}$ & $\begin{array}{c}\text { Dissertação de } \\
\text { mestrado }\end{array}$ & Pesquisa & PIRES e SOUZA \\
biográfica & \\
\hline $\begin{array}{c}\text { Mojuodara: uma } \\
\text { possibilidade de } \\
\text { trabalho com as } \\
\text { questões étnico- } \\
\text { raciais na Educação } \\
\text { Física }\end{array}$ & $\begin{array}{c}\text { UFRG Dissertação } \\
\text { de mestrado }\end{array}$ & Pesquisa & \\
\hline $\begin{array}{c}\text { Atletismo e ensino da } \\
\text { história e cultura } \\
\text { afro-brasileira: visão } \\
\text { de professores de } \\
\text { Educação Física } \\
\text { participantes de um } \\
\text { curso de extensão a } \\
\text { distância }\end{array}$ & UFC/ Unesp & Análise do discurso & BINS (2017) \\
\hline
\end{tabular}

Fonte: Os autores

Os três estudos (Quadro 2) discutem acerca da Lei $\mathrm{n}^{\circ}$ 10.639/2003, que trata do ensino da História e Cultura Afro-Brasileira. Pires e Souza (2015, p. 200) perguntam se a Educação Física, que tem se utilizado do conteúdo esporte como elemento de seu processo de ensino e aprendizagem no contexto da escola, “[...] é suficiente para inserir conteúdos referentes à cultura afro-brasileira, sem mudar a sua lógica de apropriação? ". Os autores procuram discutir as políticas educacionais e demonstrar as contradições que se apresentam no processo de ensino da cultura afro-brasileira em aulas de Educação Física, nas escolas públicas de Bagé/RS.

Ainda para esses autores, a proposta de trabalhar a Lei $\mathrm{n}^{\circ} 10.639 / 2003$ está inserida no particular da organização do trabalho pedagógico do professor de Educação Física, descontextualizado do contexto das políticas educacionais do município.

É nessa relação "entre o singular, o particular e o geral", para além do aparente, que os determinantes e as contradições se apresentam no processo de ensino da cultura afro-brasileira em aulas de Educação Física, pois, para os autores “[...] a partir da pesquisa teórica e dos dados empíricos analisados, foi possível considerar que o cumprimento da Lei a que nos referimos torna- 
se mais um compromisso repassado aos professores"(PIRES E SOUZA, 2015, p.202) do que se estabelece nas políticas educacionais do município. Também constataram a falta de conhecimento e "o estranhamento" da Lei $\mathrm{n}^{\circ} 10.639 / 2003$ e por "[...] aqueles que consideram a capoeira como única referência de desenvolvimento da cultura afro-brasileira, desconsiderando as questões sociais, históricas e culturais envolvidas no tema' (p.202).

Os autores Matthiesen e Silva (2018, p.121) procuraram “[ [...] averiguar a visão de participantes de um curso de extensão a distância sobre a adequação do Atletismo para o ensino da História e Cultura Afro-Brasileira". Utilizando, como instrumento para coleta das informações, um módulo da Plataforma AVA, os autores colheram subsídios com os professores que manifestaram aportes históricos e sociais ocorridos no interior dessa modalidade esportiva em acontecimentos olímpicos e mundial.

Os autores justificam que é preciso refletir sobre a temática referente à Lei n $10.639 / 2003$ :

“[...]é justamente a necessidade de se questionar os estereótipos que podem daí advir, como, por exemplo, a compreensão de que há uma aptidão natural dos negros para este tipo de atividades (atletismo) e não para outras, isto pois, a perspectiva de se atribuir habilidades ou aspectos inatos étnicos pode contribuir para sua desumanização e a legitimação de verdades únicas e posturas que homogeneízam as identidades e congelam as diferenças" (MATTHIESEN; SILVA,2018,p.127).

A pesquisa de Molina Neto e Bins (2017) apresenta uma discussão sobre as possibilidades do trato com as questões étnicas na Educação Física da rede municipal de ensino de Porto Alegre e tem como objetivo analisar os dados que emergiram de um estudo de caso etnográfico. Mojuodara, que significa "belo saber", na língua yorubá, trata do Projeto Político-Pedagógico da Escola M. Mario Quintana, que tem como um dos eixos a educação antidiscriminatória. Dá visibilidade às diversidades de gênero, étnico-racial e cultural, em Porto Alegre.

Os autores Molina Neto e Bins (2017, p.247) discutem a experiência de "[...] um professor da rede municipal de Porto Alegre que usa os valores civilizatórios afro-brasileiros como metodologia de trabalho para estruturar sua prática pedagógica’, perguntando “[...]quais os limites e as possibilidades para que o trabalho ou o desenvolvimento das questões étnico-raciais aconteça nas aulas de Educação Física?" (p.248).

Nos conceitos de oralidade, ancestralidade, circularidade e musicalidade, como valores civilizatórios ligados à filosofia do ubuntu, palavra africana da língua zulu, segundo os autores, o processo de se educar as relações entre pessoas de diferentes grupos étnicos tem início com mudanças no modo de se dirigirem umas às outras, rompendo com preconceitos de inferioridade. Concluem os estudos, abordando, entre outras questões, a importância de se adotar “[...] 
pensamentos e procedimentos oriundos dos princípios e valores africanos para orientar a produção científica e de se reconhecer os conhecimentos retirados da sabedoria africana que foram assimilados pela Cia ocidental' (ASANTI,1990 apud NETO; BINS,2017, p.252).

Quadro 3 - Tradição e Cultura

\begin{tabular}{|c|c|c|c|}
\hline Título do artigo & Origem & Método & Autores e ano \\
\hline $\begin{array}{c}\text { Festa, danças e } \\
\text { representações: } \\
\text { continuidade de } \\
\text { tradições e plasticidades } \\
\text { culturais }\end{array}$ & $\begin{array}{c}\text { UFES/GESPCEO } \\
\text { CEFD/Grupo de } \\
\text { estudos }\end{array}$ & $\begin{array}{c}\text { Pesquisa } \\
\text { etnográfica }\end{array}$ & ANJOS (2013) \\
\hline $\begin{array}{c}\text { A construção de uma } \\
\text { identidade quilombola a } \\
\text { partir da } \\
\text { corporal/cultura } \\
\text { prática } \\
\text { ldo jongo }\end{array}$ & UFJF/FEF & $\begin{array}{c}\text { Pesquisa } \\
\text { etnográfica }\end{array}$ & $\begin{array}{c}\text { MAROUN } \\
\text { (2014) }\end{array}$ \\
\hline $\begin{array}{c}\text { Manifestações afro- } \\
\text { brasileiras e educação } \\
\text { emancipatória para o } \\
\text { lazer }\end{array}$ & UEM & Pesquisa & $\begin{array}{c}\text { SANTOS e } \\
\text { PIMENTEL } \\
\text { (2015) }\end{array}$ \\
\hline $\begin{array}{c}\text { O tornar-se Arturo } \\
\text { revelado na festa de } \\
\text { Nossa Senhora do } \\
\text { Rosário: saberes e } \\
\text { práticas compartilhados } \\
\text { nos entrelaçamentos } \\
\text { cotidianos }\end{array}$ & UFMG & $\begin{array}{c}\text { Pesquisa } \\
\text { etnográfica }\end{array}$ & $\begin{array}{c}\text { DEBORTOLI e } \\
\text { COSTA (2016) }\end{array}$ \\
\hline $\begin{array}{c}\text { A dança afro-brasileira } \\
\text { em Londrina - PR }\end{array}$ & & & \\
\hline
\end{tabular}

Fonte: Os autores

Esse bloco (Quadro 3) discute aspectos da tradição e elementos culturais a partir de constructos de saberes e elementos corporais existentes nos movimentos corporais. Os textos ampliam suas discussões, buscando fundamentar-se em autores clássicos, como: G. Balandier (1998), para discutir tradição; S. Hall (2003) cultura; Canclini (2000) cultura popular; e Brandão (1983) que traz reflexões sobre a escola. Anteriormente, vimos três textos que abordam a Lei $\mathrm{n}^{\circ}$ 10.639/2003, contudo sem aprofundar o debate em torno da Educação Física. Percebemos que todos os textos revelam a dinamicidade em que as comunidades se envolvem, tendo o jogo e as festas como experiências culturais, proporcionando espaços de resistência, afirmação de identidade de expressões da dinâmica da vida social. Nessas experiências, ocorre o processo de aprendizagem e continuidade das tradições e saberes, que são elementos constitutivos das festas que completam os rituais. 
Anjos (2013) identifica, nas danças do ticumbi ${ }^{2}$, folia de reis e congo, manifestações populares no Norte do Estado do Espírito Santo, as quais ocorrem nos espaços coletivos das comunidades como elemento capilar dos grupos afros/negros das comunidades quilombolas e rurais do Estado. O autor discute os elementos simbólicos centrais no processo de expressão corporal que, no espaço da dança, constituem um conjunto de valores e trocas que, compartilhados, são fatores constitutivos de relações e modos de organização social. $\mathrm{O}$ autor questiona os conceitos de tradição e festa. Apoia-se nas reflexões de Georges Balandier (1998) e Evans-Pritchard (1968) que veem a tradição como um "pêndulo em movimento", enquanto festa, para Anjos, é um espaço em que são manifestadas experiências do passado e expectativas de futuro - pois o corpo que dança comunica uma identidade ao outro. A dança, como estrutura de um ritual, é a expressão cosmológica mais importante para que o rito se complete.

Se Anjos (2013) identificou nas danças elementos em que as comunidades expressam suas relações e organização social, Maroun (2014) traz em seu texto a discussão acerca da identidade de grupos quilombolas como elemento central que se reafirma no jongo, dando legitimidade e continuidade à afirmação do grupo social.

Santos e Pimentel (2015) discutem, em seus estudos, a pluralidade de culturas, mas, em contrapartida, também focalizam a carência de manifestações afro-brasileiras no âmbito das políticas públicas e sua intervenção no lazer. Os autores abordam o lazer do ponto de vista conceitual, que possui limitações, pois é tratado com características eurocêntricas (contraposição ao trabalho). Também levantam questões no âmbito das políticas públicas e na formação dos professores, observando que a intervenção profissional carece de propostas mais ligadas à pluralidade cultural, fator intrinsicamente associado à formação e à falta de pluralidade nos projetos e programas públicos.

Os autores Sborquia e Dalben (2017) desenham o mesmo quadro em seus estudos, ao discutirem a dança afro-brasileira como elemento central do processo do ensino da diversidade étnico-racial. Inicialmente, discutem que, na formação docente, é indispensável trabalhar com conteúdo que aborde elemento da cultura e da tradição afro-brasileira no ensino superior. Buscam em S. Hall (2003) firmar esse posicionamento acerca do conceito cultura, e em Canclini (2000)

\footnotetext{
O ticumbi é a denominação do baile de congos do Vale do Cricaré - região que compreende os municípios de Conceição da Barra e São Mateus -, manifestação cultural que é sobretudo uma espécie de enciclopédia virtual local, em que cada verbete se encontra delegado a um morador da vila. Cada habitante desse lugar, seja idoso ou criança, tem uma história para contar, um mito ou uma lenda para lembrar. E o principal veículo local para essa transmissão de conhecimento é o ticumbi, que em sua dança, suas letras e sua música carrega histórias e lendas que atravessam séculos. Algumas dessas histórias vieram da África, outras surgiram nas senzalas e nos quilombos que ali já existiram e dos quais há hoje remanescentes (ALVARENGA,2011.p.74)
} 
analisam a cultura popular manifestada pelo coletivo em sua transmissão de geração a geração, observando sua dinamicidade e considerando que a cultura é ressignificada ao longo do tempo.

Os autores Debortoli e Costa (2016) estudam a dinamicidade de uma comunidade rural de Minas Gerais estruturada nas relações de parentesco, de fé em atividades que se organizam socialmente pela dança. Enfocam a Lei $n^{\circ}$ 10.639/2003 e, dialogando com Brandão (1983), abordam o campo da educação em uma perspectiva ampla de mundo, dos sujeitos e das relações, contribuindo para a reflexão de práticas pedagógicas. $\mathrm{O}$ estudo revelou que a dança legitimada e estruturada em elementos simbólicos é constituinte de uma aprendizagem na prática, influenciada sistematicamente por ações cotidianas inerentes à vida social.

Quadro 4 - Raça, Eugenia e Identidade

\begin{tabular}{|c|c|c|c|}
\hline Título do artigo & Origem & Método & Autores e ano \\
\hline $\begin{array}{l}\text { Educação do corpo e } \\
\text { política: concepções de } \\
\text { raça, eugenia e higiene } \\
\text { na Educação Física } \\
\text { Argentina } \\
\end{array}$ & $\begin{array}{l}\text { UNLP/UFMG } \\
\text { Pós - graduação }\end{array}$ & $\begin{array}{c}\text { Pesquisa } \\
\text { bibliográfica }\end{array}$ & GALAK (2014) \\
\hline $\begin{array}{l}\text { O caso Tinga: } \\
\text { analisando (mais) um } \\
\text { episódio de racismo no } \\
\text { futebol sul-americano }\end{array}$ & UFPR & $\begin{array}{l}\text { Análise do } \\
\text { discurso }\end{array}$ & $\begin{array}{l}\text { LISE, SOUZA, } \\
\text { JENSEN e } \\
\text { CAPRARO } \\
(2015) \\
\end{array}$ \\
\hline $\begin{array}{l}\text { Raça e civilidade nos } \\
\text { jogos "preto x branco" }\end{array}$ & $\begin{array}{l}\text { UNIVASF/UFRJ } \\
\text { CNPQ/FAPERJ }\end{array}$ & $\begin{array}{c}\text { Pesquisa } \\
\text { bibliográfica } \\
\text { /documental }\end{array}$ & $\begin{array}{c}\text { ABRAHÃO e } \\
\text { SOARES (2016) }\end{array}$ \\
\hline $\begin{array}{c}\text { O discurso da } \\
\text { supremacia branca e o } \\
\text { esporte: um estudo a } \\
\text { partir de textos e } \\
\text { comentários na internet }\end{array}$ & USP & $\begin{array}{l}\text { Análise do } \\
\text { discurso }\end{array}$ & $\begin{array}{l}\text { TRALCI F. e } \\
\text { SANTOS (2017) }\end{array}$ \\
\hline $\begin{array}{c}\text { Futebol, raça e } \\
\text { identidade nacional: } \\
\text { uma análise do } \\
\text { desempenho dos } \\
\text { jogadores nos jogos } \\
\text { preto } \mathrm{x} \text { branco }\end{array}$ & $\begin{array}{l}\text { UNIVASF/UFRJ } \\
\text { CNPQ/FAPERJ }\end{array}$ & $\begin{array}{c}\text { Pesquisa } \\
\text { bibliográfica/ } \\
\text { documental }\end{array}$ & $\begin{array}{c}\text { ABRAHÃO e } \\
\text { SOARES (2017) }\end{array}$ \\
\hline
\end{tabular}

Fonte: Os autores

Este bloco (Quadro 4) apresenta cinco estudos, tendo como discussão central a relação de raça, eugenia, identidade e a hierarquização do corpo no esporte e na sociedade, de acordo com as referências raciais pautadas por marcadores fenotípicos e culturais os quais atribuem representações vinculadas a grupos sociais ou individualmente, nesse caso, ao negro, como agente de uma pratica social, o esporte. 
Galak (2014), abordando as passagens discursivas higienistas na passagem do século XIX para o século XX, discutindo a pretensão da educação na Argentina, utiliza-se da Educação Física como pretensão de melhorar a raça, postulado pedagógico influenciado pelo filósofo inglês Herbert Spencer. Quanto aos discursos apresentados, Galak os denomina de discursos positivos, que se traduzem na preocupação de reproduzir certos caracteres corporais reconhecidos como socialmente aceitáveis, ligados à biotipologia italiana. Para o autor, a Educação Física carrega consigo, ainda hoje, uma autonomia relativa, mediada pelas lógicas das práticas sociais.

Tratando da supremacia branca nos espaços do esporte, Tralci Filho e Santos (2017) discutem o sistema de produção, reprodução e a perpetuação de hierarquias assentadas na racialização de grupos humanos. Segundo os autores, a identidade racial de pessoas brancas, como referência universal de humanidade, conforme vimos no texto anterior, conhecida como white supremacy, criou estratégias de embranquecimento com a imigração branco-europeia para a América. Os autores citam o esporte, usando o tênis como elemento que pode contribuir para reforçar privilégios e desvantagens, conforme o pertencimento racial dos (as) atletas.

Assim, o fato de um esporte expor as potencialidades corporais contribui para que este seja entendido a partir de concepções biológicas e funcionais. É importante e merece destaque a argumentação dos autores que identificam narrativas ideológicas na construção de espaços no esporte, pois, nessas narrativas é recorrente a noção de que o esporte é um espaço de justiça e igualdade de oportunidades. Em última instância, um lugar no qual os vencedores e perdedores são definidos a partir do esforço individual ou das somas dos esforços individuais.

Entretanto, tal interpretação do esporte, como "parábola" de ganho e recompensa pelo esforço, também pode contribuir para encobrir relações de dominação, e subordinação e de desigualdades sociais. Ser vencedor no esporte é uma questão de esforço individual, e o esporte, como prática social, por conseguinte, é mais permeável ao racismo pseudocientífico e à legitimação de desigualdades.

Lise, Souza, Jensen e Capraro (2015) discutem a recorrência e casos de racismo no futebol brasileiro e sul-americano. Enfocando o caso Tinga, que sofreu preconceito de racismo em pleno jogo entre uma equipe peruana e outra brasileira, os autores discutem o preconceito racial voltado para o conceito sociológico, conforme Nogueira (2007).

$\mathrm{Na}$ citação de Nogueira (2007) preconceito racial é uma disposição (ou atitude) desfavorável, culturalmente condicionada, em relação aos membros de uma população, os quais se têm como estigmatizados, seja devido à aparência, seja devido a toda ou parte da ascendência étnica que lhes é atribuída. Constitui-se num processo de hierarquização, exclusão e discriminação contra um indivíduo ou toda uma categoria social que é definida como diferente com base em alguma 
marca física externa (real ou imaginada), que culturalmente define padrões de comportamentos. Para o autor a recorrência do preconceito racial no futebol ocorre porque as "penas aplicadas aos infratores são demasiadas brandas, possibilitando a recorrência desse tipo de conduta no campo futebolístico" (NOGUEIRA,2007, p.292)

Utilizando interpretações freirianas em "Casa grande e senzala", os autores Abrahão e Soares (2016) tratam os textos num tom harmonioso, considerando as relações ocorridas nos jogos de futebol de preto x branco nos anos idos de 1930, em São Paulo. No primeiro texto (2016), os autores buscam explicitar o conceito de raça e civilidade. Citando D'Adesky (2005) que debate os elementos raciais, os autores apontam:

[...] os avanços das pesquisas genéticas [as quais] trouxeram a conclusão de que raça é uma categoria desprovida de valor científico. Todavia, a desconstrução científica da raça biológica não fez desaparecer a evidência da raça como marcador simbólico, isto é, o modo pelo qual as culturas passaram a ressignificar as semelhanças e as diferenças fenotípicas, morfológicas e sociais entre os humanos (ABRAHÃO; SOARES, 2016, p. 1140).

Em seguida, é Dunning (2014) que aparece nesse mesmo texto para tratar da violência no campo esportivo.

Para Abrahão e Soares (2016), após 40 anos da abolição da escravatura e comemorando a libertação no dia 13 de maio, os jogos de futebol poderiam constituir um "campo de luta simbólico", despertar, portanto, ranços e remorsos herdados, lembranças da escravidão e da hierarquia inferior em relação ao branco.

Usando análises da imprensa jornalística da época, os autores concluíram que os jogos dos preto $\mathrm{x}$ branco tiveram ausência de manifestações violentas, afirmando, portanto, o potencial civilizatório da nação brasileira com o convívio pacífico entre as "raças". Na conclusão de seus estudos, os autores manifestam uma análise "apaziguadora" na existência das relações entre os times, atribuindo que a supremacia do time dos pretos nos jogos serviu como um meio de reforço dos seus capitais para o futebol e para contestar muitas marcas preconceituosamente imputadas às “pessoas de cor” na época, como a violência.

Já no segundo texto, Abrahão e Soares (2017), utilizando do mesmo caminho metodológico, procuram analisar o desempenho dos jogadores nos jogos preto $\mathrm{x}$ branco ocorridos nas décadas de 20 e 30 do século passado. Mesmo que trabalhando com os conceitos de raça e identidade nacional, no texto, não identificamos uma discussão acerca destes. Embora esses conceitos soem de forma elogiosa à identidade dos pretos, em relação ao fato de jogarem futebol, no mesmo nível dos 
brancos, os autores discutem a existência de estereótipos positivos sobre as qualidades corporais da "raça negra".

$\mathrm{Na}$ análise dos discursos jornalísticos, segundo os autores, a imprensa construía reiterados elogios associados ao coletivo de pretos e valores individuais, independentemente do resultado da partida. Para confirmar a ideia da potencialidade do jogador preto no campo de futebol, mesmo com o resultado desfavorável, os comentários eram elogiosos, dirigindo, assim, adjetivos positivos aos pretos.

Concluiu-se que o espaço do futebol estava dado e desenhado como um espaço de vocação "inata" dos negros para as atividades corporais e/ou artísticas. Mesmo que exista uma grande problemática em se afirmar certa "facilidade biológica" de alguma raça/etnia, os autores o fazem constatando que o negro é posicionado de forma superior em determinados espaços de prática social, pois possui em sua linguagem corporal a ginga advinda dos grupos étnicos afros. Esse esporte também é visto pela sociedade como um possível meio do negro ascender socialmente, e não vimos tal desconstrução pelos autores do texto.

Quadro 5 - Marketing e estereótipos

\begin{tabular}{|c|c|c|c|}
\hline Título do artigo & Origem & Método & Autores e ano \\
\hline $\begin{array}{c}\text { Marketing esportivo, } \\
\text { cultura hip hop e } \\
\text { consumo: uma análise } \\
\text { da campanha }\end{array}$ & Université de & Análise do & GODOI, \\
"é possível!" & discurso & DUMMEL e \\
SILVA (2016)
\end{tabular}

Fonte: Os autores

Esse bloco (Quadro 5) discute, em seus dois artigos, as representações sociais de grupos étnicos e suas relações com o consumo, marketing e estereótipos que os perseguem.

O artigo de Godoi, Dummel e Silva (2016) investigou uma campanha de marketing esportivo veiculada pela webnet, destinada aos jovens das periferias urbanas brasileiras. Eles analisaram criticamente os discursos e estratégias discursivas e ideológicas dessa campanha e também os comentários dos internautas, usando a análise do discurso. 
Os autores se utilizaram dos estudos de Mainguenau (2005) e Bakhtin (1997) para relacionar os discursos e as relações sociais presentes no marketing. Buscaram em Frederik/Fredric Jameson (2001) fundamentos para discutir a conceituação de consumo. A campanha se tratava da empresa Nike que lançou o tênis AF1 Brasil, o manifesto e o documentário "É possível!", na Central Única das Favelas (Cufa), de Madureira-RJ, num evento com apresentações de basquete de rua, de B-boys e de grafite. Vale notar que a data do lançamento, dia da Independência do Brasil, foi significativa, pois tanto o manifesto quanto o documentário vão aludir à “independência das ruas". Na época, a Nike criou uma página no Facebook para apresentar informações sobre o projeto, o produto, e os protagonistas: dois jogadores de basquete, três rappers e um grafiteiro.

Os autores também citaram a problemática de uma empresa de produtos esportivos organizando atividades culturais e esportivas na periferia, realizando uma função que deveria ser do Estado. Alertam para o perigo de os jovens serem socializados mediados por uma marca, logo, envolvidos em ideais de consumo, antes e acima da necessária compreensão da verdadeira cidadania de uma coletividade.

O artigo de De Migliorati, Aranda e Gonzalez (2016) se inicia conceituando raça e etnia. Buscando o conceito em Macionis (2007), raça é entendida como uma categoria de indivíduos que compartilham certas semelhanças hereditárias socialmente significativas. O conceito de "etnia" conferido pelos autores refere-se ao grupo de pessoas que compartilham o mesmo patrimônio cultural, possuem ancestrais comuns, falam a mesma língua, praticam a mesma religião, compartilham costumes e identidade social. Enquanto o primeiro conceito tem mais influência sobre fatores biológicos, o último tem um caráter cultural.

No artigo, os autores utilizaram, para distinguir as pessoas dos diferentes grupos étnicos, o termo "branco" para os da Europa e do Oriente Médio, e "negro ou afro-americano" para os grupos raciais negros da África. Ambos os conceitos são construções sociopolíticas e não devem ser interpretados separadamente apenas como científicas ou somente antropológicas.

Com o objetivo de identificar a presença de estereótipos étnicos ligados aos atletas negros na carreira de atletismo, basquete e natação em uma Faculdade de Ciências Motoras na Itália, a pesquisa ocorreu por meio de questionários. Para abordar o grau de credibilidade do estudo, as informações obtidas e as categorias de análise foram submetidas a julgamento de especialistas. O artigo constatou a presença de estereótipos negativos e racistas. Ao serem questionados, os alunos enfatizaram que os negros possuem facilidades, mas também dificuldades biológicas nas modalidades esportivas.

De acordo com o texto, os estereótipos ainda prevalecem no campo das atividades físicas, afetando negativamente a iniciação de jovens atletas e a participação justa e igualitária de diferentes 
grupos étnicos nas múltiplas disciplinas esportivas. Os autores concluíram sobre a importância do papel pedagógico dos educadores que precisam de uma reformulação e reelaboração antirracista em seus materiais e propostas curriculares. Os resultados das entrevistas apresentaram estereótipos negativos que impedem uma educação esportiva proporcionadora de inclusão social liberta de qualquer estereótipo preconceituoso e racista.

Nesse sentido, as ideias estereotipadas influenciam o crescimento, desenvolvimento e identificação de adolescentes, desempenhando um papel fundamental na construção de sua identidade. Assim, o esporte, que deveria favorecer o encontro intercultural, pode aumentar a discriminação e o racismo.

Quadro 6 - Políticas Públicas

\begin{tabular}{|c|c|c|c|}
\hline Título do artigo & Origem & Método & Autores e ano \\
\hline Políticas Públicas para & UFMS/UFJF/UCB & Pesquisa & NEVES, \\
minorias étnico-raciais, & & documental & GOLIN, LIRA, \\
mulheres e juventude: & & SAMPAIO E \\
notas introdutórias sobre & & & ASSUMPÇÃO \\
as áreas de saúde, & & & $(2015)$ \\
trabalho, educação, & & & \\
esporte e lazer & & & \\
\hline
\end{tabular}

Fonte: Os autores

Os autores Neves, Golin, Lira, Sampaio e Assumpção (2015) realizaram um levantamento bibliográfico e documental de cunho qualitativo, utilizando documentos governamentais publicados sobre políticas públicas (Quadro 6). Os autores selecionaram e analisaram publicações oficiais brasileiras voltadas às áreas de esporte e lazer, buscando identificar como esses documentos abordam temas como questões étnico-raciais, no tocante às mulheres e à juventude no esporte e lazer.

Os autores analisaram a juventude negra brasileira, delineando que a história de vida desse grupo social é marcada pela exclusão, por altas taxas de mortalidade, pela limitada ascensão social e pelo precário acesso à educação, cultura e lazer. Quanto à política pública, conceituaram como ações “[...] resultante da atividade política, [a qual requer] várias ações estratégicas destinadas a implementar os objetivos desejados" (ASSUMPÇÃO,2010, p.14). Nessas ações, segundo os autores, constam metas e planos do governo que visam à melhoria das condições gerais de vida dos membros de um grupo social e do poder público. 
Criticamente, os autores, em suas análises, apontam esses documentos voltados para a atenção aos grupos minoritários, jovens negros e mulheres, diante de tamanha desigualdade nas condições de vida social. Os estudos dos autores evidenciam que, embora as políticas públicas procurem alcançar os grupos minoritários na vivência e experimentação do esporte e lazer, há desigualdades nas oportunidades de experimentação, indicando que os processos de formulação dessas políticas públicas de esporte e lazer necessitam ser revistos para que assumam a "[...] visibilidade dos grupos minoritários e passem realmente a considerar na estruturação das políticas públicas o direito social desses grupos à estas práticas" (NEVES; GOLIN; LIRA; SAMPAIO; ASSUMPÇÃO, 2015, p.945).

\section{Considerações Finais}

Ao final dos estudos, ao analisar todas as publicações, tivemos uma visão geral da área da temática que trata dos elementos étnico-raciais. A ordenação em blocos permitiu-nos perceber as características e o tratamento teórico do objeto, além das lacunas ainda existentes.

No entanto, vamos apontar algumas limitações que identificamos ao realizar as análises. Ao identificar conceitos que nos fornecessem elementos relacionados com a temática étnico-racial, vimos que, embora os textos apontassem a discussão para o conceito do objeto do estudo (identidade, étnica, etc.), não identificamos neles tratamento teórico como elemento principal do estudo. Observamos que as conceituações dos objetos de estudos nos artigos analisados são amplas/genéricas e a discussão dos conceitos sequer indica as fontes utilizadas e, por conseguinte, essas não foram citadas/indicadas. $\mathrm{Na}$ análise dos textos, identificamos cinco autores clássicos os quais foram citados para consubstanciar os conceitos/discussões.

A apresentação dos resumos dos artigos e as palavras-chave, foram fatores que dificultaram as análises, pois alguns resumos se apresentam muito sucintos e outros confusos ou incompletos, sem informação sobre o tipo de pesquisa e os procedimentos de coleta de dados. Alguns sequer deixavam explícitos os objetivos do estudo e vários confundiam a metodologia da pesquisa com os procedimentos e instrumentos utilizados, motivo que nos fez construir quadros para dar conta desse fato. Por exemplo, os descritores não estavam explícitos de acordo com as palavras-chave indicadas. Em continuidade a esse fato, os resumos restritos, sem especificação do tipo de estudo pelo autor, levaram-nos a defini-lo, após a leitura do texto na íntegra, pelo contexto em que foi realizada a pesquisa e pelas técnicas utilizadas para coleta dos dados. Fomos cuidadosos para manter uma melhor aproximação com a intenção do autor do trabalho. 
Essas limitações dificultaram e, em alguns casos, também nos prejudicaram em categorizar/classificar o conteúdo de determinados artigos. Também vimos que, em relação ao título, os trabalhos trouxeram-nos dificuldades, pois eram amplos e difusos, não revelando indicações do tema da pesquisa.

Notamos que os artigos que tratavam de um mesmo elemento favoreceram a discussão do conceito e as discussões se estreitaram entre si. "Festa" foi um elemento textual que aglutinou cinco artigos, o que proporcionou discussões sobre o aspecto redacional dos textos que, embora distantes nos objetivos, estavam próximos ao método de pesquisa, a etnografia. Um segundo elemento, o "futebol”, aparece com distintas discussões, no entanto foi possível classificá-lo no mesmo bloco de análise.

Tendo em vista a diversidade de conceitos referentes às questões étnico-raciais discutidas no interior dos artigos, identificamos os que mais apareceram nos textos. Analisados: sete artigos fizeram citação ou discutiram o conceito de raça; quatro elaboraram a discussão do conceito etnia; apenas um artigo discutiu o processo de eugenia existente na Educação Física. Já o conceito identidade, praticamente, contingenciou o total das obras analisadas, porém sem discussão profunda. Embora o conceito se encontrasse em posição de elemento textual e situacional, delimitando o tema do trabalho, do objeto de estudo ou a discussão no corpus da redação do texto, nos pareceu que conceituá-lo foi uma tarefa difícil, pelo fato de ser dinâmico e não atender aos propósitos e objetivos do artigo/estudo. No entanto congelá-lo no corpo do texto, como vimos, analiticamente, não fornece elementos que subsidiem ou dê sustentação teórica aos estudos publicados.

Dessa forma, por se constituir um elemento textual e conceitual, como identidade de gênero, identidade social, identidade cultural, identidade étnica, identidade de grupo etc., entendemos que o conceito merece e deve ser pertinente à discussão conceitual no corpo do texto, porém, no decorrer da análise, observamos que as conceituações advindas, ou a falta desta, se mostraram genéricas.

É cabível acrescentar que na área da Educação Física, principalmente nos artigos presentes, foi observada uma discussão, mesmo que mínima, na formação de professores, currículo, formação continuada e/ou nas políticas educacionais. No entanto, o interesse pelos temas educacionais que tratam das questões étnico-raciais não tem sido suficiente para que mudanças significativas ocorram nos espaços de formação escolares ou não escolares. Desta forma, este estudo também pode contribuir para novas pesquisas nos estudos étnico-raciais que envolvam a Educação Física.

Finalizando e, entendendo que o "estado da arte" é uma narrativa da produção acadêmica que muitas vezes revela a história e o amadurecimento da pós-graduação, da iniciação científica, podemos identificar algumas marcas de convencionalidade, entre as quais destacamos certa 
padronização quanto à estrutura composicional: anunciam o que se pretendeu investigar, descrevem os resultados alcançados mas, em sua maioria, as publicações apresentam uma linguagem descritiva.

\section{REFERÊNCIAS}

ALVARENGA, Luciana. O TICUMBI: imagens e memória da Vila de Itaúnas. Arte \& ensaios. Revista do ppgav/eba/ufrj • n. 23, nov, p. 73-79, 2011.

BAKHTIN, Mikhail. Marxismo e filosofia da linguagem: problemas fundamentais do método sociológico na ciência da linguagem. São Paulo: Hucitec, 1997.

CARVALHO, Marcelo Pagliosa. História da educação da população negra: estado da arte sobre a educação e relações étnico-raciais (2003 - 2014). Educar em Revista, Curitiba, v. 34, n. 69, p. 211 $230,2018$.

D'ADESKY, Jacques. Racismos e anti-racismos no Brasil: pluralismo étnico e multiculturalismo. Rio de Janeiro: Pallas, 2005.

EVANS-PRITCHARD, Edward Evan. Les nuer: description des modes de vie et des institutions politiques d'un peuple nilote. Paris: Gallimard, 1968.

GOMES, Nilma Lino. O movimento negro educador: saberes construídos nas lutas por emancipação. RJ: Vozes, 2017.

GIDDENS, Anthony. Raça, etinicidade e migração In: Sociologia. 4.ed. Porto Alegre: Artmed, p. 205. 2005

MACIONIS, John Joseph. Sociología. Madrid: Pearson Prentice Hall, 2007.

NOGUEIRA, Oracy. Preconceito racial de marca e preconceito racial de origem: sugestão de um quatro de referência para a interpretação do material sobre relações raciais no Brasil. São Paulo: Tempo Social, 2007.

SALES, Leydiane Vitória; ALMEIDA, Neil Franco Pereira de. Diversidade racial e Educação Física escolar na Revista Brasileira de Ciências do Esporte (1979-2013). In:

Conexões. Revista da Faculdade de Educação Física da Unicamp, Campinas, v. 13, n. 1, p. 129161, jan./mar. 2015.

\section{NOTAS DE AUTOR}

\section{AGRADECIMENTOS}

Não se aplica. 
CONTRIBUIÇÃO DE AUTORIA

Concepção do manuscrito: P.T. Monteiro; J.L.Anjos

Coleta de dados: P.T. Monteiro; J.L.Anjos

Análise de dados: P.T. Monteiro; J.L.Anjos

Discussão dos resultados: J. T. Sobrenome

Produção do texto: P.T. Monteiro; J.L.Anjos

Revisão e aprovação: P.T. Monteiro; J.L.Anjos

FINANCIAMENTO

Apoio Edital FAPES na forma de bolsa PIIC_2018-19.

CONSENTIMENTO DE USO DE IMAGEM

Não se aplica.

\section{APROVAÇÃO DE COMITÊ DE ÉTICA EM PESQUISA}

Não se aplica.

\section{CONFLITO DE INTERESSES}

Não se aplica.

\section{LICENÇA DE USO}

Os autores cedem à Motrivivência - ISSN 2175-8042 os direitos exclusivos de primeira publicação, com o trabalho simultaneamente licenciado sob a Licença Creative Commons Attribution Non-Comercial ShareAlike (CC BY-NC SA) 4.0 International. Esta licença permite que terceiros remixem, adaptem e criem a partir do trabalho publicado, desde que para fins não comerciais, atribuindo o devido crédito de autoria e publicação inicial neste periódico desde que adotem a mesma licença, compartilhar igual. Os autores têm autorização para assumir contratos adicionais separadamente, para distribuição não exclusiva da versão do trabalho publicada neste periódico (ex.: publicar em repositório institucional, em site pessoal, publicar uma tradução, ou como capítulo de livro), com reconhecimento de autoria e publicação inicial neste periódico, desde que para fins não comerciais e compartilhar com a mesma licença.

\section{PUBLISHER}

Universidade Federal de Santa Catarina. Programa de Pós-Graduação em Educação Física. LaboMídia - Laboratório e Observatório da Mídia Esportiva. Publicado no Portal de Periódicos UFSC. As ideias expressadas neste artigo são de responsabilidade de seus autores, não representando, necessariamente, a opinião dos editores ou da universidade.

\section{EDITORES}

Mauricio Roberto da Silva, Giovani De Lorenzi Pires, Rogério Santos Pereira.

\section{HISTÓRICO}

Recebido em: 21 de Março de 2019.

Aprovado em: 01 de Setembro de 2019. 